\title{
The Connection Between the Nervous System and Machines: Commentary
}

\author{
Giacomo Valle ${ }^{1,2}, \mathrm{MSc}$ \\ ${ }^{1}$ The Biorobotics Institute, Sant'Anna School of Advanced Studies, Pisa, Italy \\ ${ }^{2}$ Translational Neural Engineering Lab, École Polytechnique Fédérale de Lausanne, Lausanne, Switzerland
}

\section{Corresponding Author:}

Giacomo Valle, MSc

The Biorobotics Institute

Sant'Anna School of Advanced Studies

Viale Rinaldo Piaggio 34

Pisa,

Italy

Phone: 393405454807

Email: vallegiacomo@gmail.com

\section{Related Article:}

Comment on: http://jmir.org/2019/10/e16194/

\begin{abstract}
Decades of technological developments have populated the field of brain-machine interfaces and neuroprosthetics with several replacement strategies, neural modulation treatments, and rehabilitation techniques to improve the quality of life for patients affected by sensory and motor disabilities. This field is now quickly expanding thanks to advances in neural interfaces, machine learning techniques, and robotics. Despite many clinical successes, and multiple innovations in animal models, brain-machine interfaces remain mainly confined to sophisticated laboratory environments indicating a necessary step forward in the used technology. Interestingly, Elon Musk and Neuralink have recently presented a new brain-machine interface platform with thousands of channels, fast implantation, and advanced signal processing. Here, how their work takes part in the context of the restoration of sensory-motor functions through neuroprostheses is commented.
\end{abstract}

(J Med Internet Res 2019;21(11):e16344) doi: 10.2196/16344

\section{KEYWORDS}

brain-machine interfaces; neural electrodes; neural recording; neurostimulation; sensory-motor dysfunctions

Significant research in biology, medicine and engineering has sought to obtain effective solutions to improve quality of life of human subjects affected by sensory-motor disorders. Neuroprosthetics are implantable devices designed to replace or improve the function of a disabled part of the nervous system [1]. This technology is relatively recent, as the first neuroprosthetic device successfully implanted was a cochlear implant in 1957 [2]. Since then, such an approach has been expanded to many different applications, which include motor prosthetics [3-6], sensorimotor prosthetics [7-9], visual prosthetics [10,11], and cognitive prosthetics [12].

Up till now, patients who used brain-machine interfaces have had a quite poor perception of the instantaneous behavior, position, or motion of the robotic device, which has prevented them from operating in fully closed-loop and natural control. The restoration of sensory feedback and voluntary control, along with the development and successful integration of these sensor modalities, is a mandatory step towards the realization of future bidirectional neuroprostheses [13].

The challenges described above can be addressed by creating a brain-machine interface that utilizes the processing power of the human brain to control the robotic device. Directly connecting to the human nervous system means closing the gap between user intent and the expected behavior of the apparatus. Furthermore, generating a shorter loop between user intent and device behavior or motion (by eliminating part of the low-level sensor-based control) will allow for easier control, a reduced learning investment, and a reduced cognitive burden of operating the device.

Neural interfaces play a pivotal role in the efficacy of a neuroprosthetic. Due to their ability to read out electrical activity from the nervous system, it is possible to decode signals into cognitive, sensory, or motor information through the use of 
computational methods. This information can then be used to control a prosthetic device, robot, or computer. It also induces better understanding of brain behavior through the recording of neural activity, providing information about sensory areas responsible for hearing or sight (sensory prosthetics), or helping to regulate malfunctioning motor functions (motor prosthetics). On the other hand, pacemaker or bladder control neuroprosthetics also use similar physical principles, targeting the autonomic nervous system and helping patients with paraplegia due to spinal cord damage [14].

In a recent article, Elon Musk and his company Neuralink presented a new platform to target the brain for neuroprosthetic applications [15]. They used arrays of small and flexible electrodes (called threads), with 3072 electrodes per array, distributed across 96 threads. They also developed a neurosurgical robot able to insert six threads (192 electrodes) per minute. Each thread can be individually inserted into the brain with high precision, avoiding surface vasculature and targeting specific brain zones. The electrode array is packaged into a small implantable device that contains custom chips for low power, onboard amplification, and digitization. Moreover, since neural spikes in a brain-machine interface must be detected in real time to maximize decoding efficacy, Neuralink has developed a custom online spike-detection software that has achieved a spiking yield of up to $70 \%$ in chronically implanted electrodes. Musk's long-term idea consists of enabling humans to connect their brains to machines, and Neuralink's approach to a brain-machine interface has shown unprecedented packaging density, extensibility, and scalability in a clinically relevant package. The main properties of the neural electrodes are related to their biocompatibility, long-term stability, and recording/stimulating selectivity when interfacing with both peripheral and central nervous systems $[16,17]$. Therefore, more tests should be performed for a complete validation of this new platform. This step is not trivial, as it is crucial to show the possible translation of this approach to humans. Further, it is necessary to demonstrate the effective benefits of using this new technology in comparison to other techniques that have been widely tested in the previous decades. The hypothetical complete brain-machine connection has become a closer possibility, but it is not ready just yet.

In this field, many devices and smart materials have been presented as effective solutions to interfacing with nervous tissues, enabling an intimate connection between the brain and machines in animals and even in humans [18]. Understanding how to interact with the brain using advanced algorithms has become of great clinical interest now, both to decode neural information [19] and to encode natural sensations by exploiting biomimetic neurostimulation strategies [20]. Moreover, advanced data processing methods have to be developed to bring these technologies to real life application. In this direction, new tools like machine learning and quantum computing will help to bring this concept to reality.

In the near future, neurotechnologies will continue to grow. More accurate and advanced computer simulations (eg, computational modelling) will allow researchers to test and validate these technologies even quicker. Implantable neurotechnologies will literally become part of us. Direct bidirectional communication between the brain and external devices, the transformation that this connection brings about, and the blurring of the boundaries between humans and machines, are issues that raise several ethical, social, and cultural concerns. Personal identity, physical integrity, and the human dignity [21] of people using the next generation of brain-machine interfaces will surely require further attention.

\section{Conflicts of Interest}

None declared.

\section{References}

1. Borton D, Micera S, Millán JDR, Courtine G. Personalized neuroprosthetics. Sci Transl Med 2013 Dec 06;5(210):210rv2-210rv2. [doi: 10.1126/scitranslmed.3005968] [Medline: 24197737]

2. Eisen MD. Djourno, Eyries, and the first implanted electrical neural stimulator to restore hearing. Otol Neurotol 2003 May;24(3):500-506. [doi: 10.1097/00129492-200305000-00025] [Medline: 12806307]

3. van den Brand R, Heutschi J, Barraud Q, DiGiovanna J, Bartholdi K, Huerlimann M, et al. Restoring voluntary control of locomotion after paralyzing spinal cord injury. Science 2012 Jul 01;336(6085):1182-1185 [FREE Full text] [doi: 10.1126/science.1217416] [Medline: 22654062]

4. Collinger JL, Wodlinger B, Downey JE, Wang W, Tyler-Kabara EC, Weber DJ, et al. High-performance neuroprosthetic control by an individual with tetraplegia. The Lancet 2013 Feb;381(9866):557-564. [doi: 10.1016/s0140-6736(12)61816-9]

5. Wagner FB, Mignardot J, Le Goff-Mignardot CG, Demesmaeker R, Komi S, Capogrosso M, et al. Targeted neurotechnology restores walking in humans with spinal cord injury. Nature 2018 Nov 31;563(7729):65-71. [doi: 10.1038/s41586-018-0649-2] [Medline: 30382197 ]

6. Hochberg LR, Bacher D, Jarosiewicz B, Masse NY, Simeral JD, Vogel J, et al. Reach and grasp by people with tetraplegia using a neurally controlled robotic arm. Nature 2012 May 16;485(7398):372-375 [FREE Full text] [doi: 10.1038/nature11076] [Medline: 22596161]

7. Flesher SN, Collinger JL, Foldes ST, Weiss JM, Downey JE, Tyler-Kabara EC, et al. Intracortical microstimulation of human somatosensory cortex. Sci Transl Med 2016 Oct 19;8(361):361ra141-361ra141. [doi: 10.1126/scitranslmed.aaf8083] [Medline: 27738096] 
8. Raspopovic S, Capogrosso M, Petrini FM, Bonizzato M, Rigosa J, Di Pino G, et al. Restoring natural sensory feedback in real-time bidirectional hand prostheses. Sci Transl Med 2014 Mar 05;6(222):222ra19-222ra19 [FREE Full text] [doi: 10.1126/scitranslmed.3006820] [Medline: 24500407]

9. Petrini FM, Bumbasirevic M, Valle G, Ilic V, Mijović P, Cvancara P, et al. Sensory feedback restoration in leg amputees improves walking speed, metabolic cost and phantom pain. Nat Med 2019 Sep 9;25(9):1356-1363. [doi:

10.1038/s41591-019-0567-3] [Medline: 31501600]

10. Dobelle WH, Mladejovsky MG, Girvin JP. Artifical vision for the blind: electrical stimulation of visual cortex offers hope for a functional prosthesis. Science 1974 Mar 01;183(4123):440-444. [doi: 10.1126/science.183.4123.440] [Medline: 4808973]

11. da Cruz L, Dorn JD, Humayun MS, Dagnelie G, Handa J, Barale P, Argus II Study Group. Five-Year Safety and Performance Results from the Argus II Retinal Prosthesis System Clinical Trial. Ophthalmology 2016 Oct;123(10):2248-2254 [FREE Full text] [doi: 10.1016/j.ophtha.2016.06.049] [Medline: 27453256]

12. Andersen RA, Hwang EJ, Mulliken GH. Cognitive neural prosthetics. Annu Rev Psychol 2010;61:169-90, C1 [FREE Full text] [doi: 10.1146/annurev.psych.093008.100503] [Medline: 19575625 ]

13. SensArs - Neuroprosthetics. 2019. URL: https://www.sensars.com/ [accessed 2019-10-26]

14. Creasey GH, Grill JH, Korsten M, Betz R, Anderson R, Walter J, Implanted Neuroprosthesis Research Group. An implantable neuroprosthesis for restoring bladder and bowel control to patients with spinal cord injuries: a multicenter trial. Arch Phys Med Rehabil 2001 Dec;82(11):1512-1519. [doi: 10.1053/apmr.2001.25911] [Medline: 11689969]

15. Musk E, Neuralink. An Integrated Brain-Machine Interface Platform With Thousands of Channels. J Med Internet Res 2019 Oct 31;21(10):e16194 [FREE Full text] [doi: 10.2196/16194] [Medline: $\underline{31642810}$ ]

16. Navarro X, Krueger TB, Lago N, Micera S, Stieglitz T, Dario P. A critical review of interfaces with the peripheral nervous system for the control of neuroprostheses and hybrid bionic systems. J Peripher Nerv Syst 2005 Oct;10(3):229-258. [doi: 10.1111/j.1085-9489.2005.10303.x] [Medline: 16221284 ]

17. Lebedev MA, Nicolelis MAL. Brain-machine interfaces: past, present and future. Trends Neurosci 2006 Oct;29(9):536-546. [doi: 10.1016/j.tins.2006.07.004] [Medline: 16859758]

18. Schiavone G, Lacour SP. Conformable bioelectronic interfaces: Mapping the road ahead. Sci Transl Med 2019 Jul 31;11(503):eaaw5858. [doi: 10.1126/scitranslmed.aaw5858] [Medline: 31366582]

19. Schwemmer MA, Skomrock ND, Sederberg PB, Ting JE, Sharma G, Bockbrader MA, et al. Meeting brain-computer interface user performance expectations using a deep neural network decoding framework. Nat Med 2018 Nov;24(11):1669-1676. [doi: 10.1038/s41591-018-0171-y] [Medline: 30250141]

20. Valle G, Mazzoni A, Iberite F, D'Anna E, Strauss I, Granata G, et al. Biomimetic Intraneural Sensory Feedback Enhances Sensation Naturalness, Tactile Sensitivity, and Manual Dexterity in a Bidirectional Prosthesis. Neuron 2018 Oct 10;100(1):37-45.e7 [FREE Full text] [doi: 10.1016/j.neuron.2018.08.033] [Medline: 30244887]

21. Drew L. The ethics of brain-computer interfaces. Nature 2019 Jul 24;571(7766):S19-S21. [doi: 10.1038/d41586-019-02214-2] [Medline: $\underline{31341310]}$

Edited by G Eysenbach; submitted 20.09.19; peer-reviewed by A Korchi; comments to author 12.10.19; revised version received 26.10.19; accepted 31.10.19; published 06.11.19

Please cite as:

Valle $G$

The Connection Between the Nervous System and Machines: Commentary

J Med Internet Res 2019;21(11):e16344

URL: https://www.jmir.org/2019/11/e16344

doi: $10.2196 / 16344$

PMID: $\underline{31692449}$

(C) Giacomo Valle. Originally published in the Journal of Medical Internet Research (http://www.jmir.org), 06.11.2019. This is an open-access article distributed under the terms of the Creative Commons Attribution License (https://creativecommons.org/licenses/by/4.0/), which permits unrestricted use, distribution, and reproduction in any medium, provided the original work, first published in the Journal of Medical Internet Research, is properly cited. The complete bibliographic information, a link to the original publication on http://www.jmir.org/, as well as this copyright and license information must be included. 